\title{
Physical Activity and Body Composition: A 20-Month Prospective Study of Middle-Age Women
}

\author{
Travis R. Peterson ${ }^{1, *}$ and Larry A. Tucker ${ }^{2}$ \\ ${ }^{1}$ Health Science Dept., University of Colorado at Colorado Springs, 1420 Austin Bluffs Pky, Colorado Springs, Colorado; \\ ${ }^{2}$ Department of Exercise Sciences, Brigham Young University, Provo, Utah
}

\begin{abstract}
:
Objective: To determine the extent that physical activity accounts for changes in body composition and body weight over time, independent of dietary intake and other potential confounding factors.

Methods and Procedures: A cohort of 256 women ages 35-45 at baseline participated in the study. A prospective design was utilized with baseline and follow up assessments 20-months apart. Primary assessments included body weight, body fat percentage, physical activity assessed by accelerometery, and 7-day weighed diet record. Regression analysis was used to determine the extent to which changes in physical activity contributed to changes in body fat percentage and body weight over the study period. Relative risk for change in body fat and weight was calculated using Poisson regression.

Results: Over the study period, there were significant changes in body fat percentage, body weight and physical activity. Change in physical activity was a significant predictor of changes in body fat and body weight over the 20-month study period. The impact of change in physical activity on body weight remained significant after controlling for dietary intake and other potential confounding variables. Those in the lower levels of physical activity also had an increased risk of both weight and fat gain over the study period.

Discussion: Based on these results, change in physical activity status is an independent predictor of body fat and body weight change over time. Those who are less active also have increased risk of weight and fat gain over time independent of dietary factors.
\end{abstract}

Key Words: Physical activity, Body composition, Weight change, Accelerometers, Prospective design, Energy intake.

\section{INTRODUCTION}

Obesity has become one of the most important public health challenges of our time. It has been predicted that obesity will replace cigarette smoking as the major killer of Americans this century [1]. Research shows that excess body weight directly leads to many health problems and often contributes indirectly to other serious disorders including Type II diabetes, coronary heart disease, high blood pressure, hyperlipidemia, various cancers, osteoarthritis, gallbladder disease, stroke, and allcause mortality [2-5]. Obese individuals also have a diminished quality of life. This is demonstrated by reduced self-esteem [6], negative dispositions including discrimination by others $[7,8]$, and a self-perceived reduction in overall quality of life [8].

Research has shown that obesity results from the interaction and interdependence of multiple factors over time. One of the primary factors involved in the development of obesity is lack of physical activity. Based on several comprehensive reviews and meta-analyses, it appears that there is some relationship

*Address correspondence to this author at the Health Science Dept., University of Colorado at Colorado Springs, PO Box 7150, Colorado Springs, CO 80933; Tel: 719-262-4466; Fax: 719-262-4416; E-mail: tpeterso@uccs.edu between physical activity and weight. First, physical activity has a desirable impact on weight and body composition. Physical activity promotes fat loss and plays a role in the preservation of lean body mass. Second, it is likely that there is a dose response relationship between physical activity and weight loss in that the rate of weight loss is associated with the volume of activity performed [9-12]. Based on current knowledge it seems that physical activity has a positive influence on body composition. However, the impact of physical activity on body composition over time has not been well examined and remains elusive. According to a comprehensive review by DiPietro [13], there are too few longitudinal data on how physical activity affects the risk, or development, of weight gain or overweight in the general population. Furthermore, many investigations in this area have used weak measurement methods, such as self-reported measures of physical activity, and assessments of body weight or skin-folds to index body composition [9]. Lack of precision in the measurement of physical activity and/or body composition tends to attenuate the magnitude of their true association, which may account for the relatively low correlations seen between physical activity and body composition in epidemiologic studies. Moreover, to date, very few investigations have controlled for differences in energy intake while studying the relation between physical activity and body 
composition, despite it making up one-half of the energy balance model.

The purpose of the present study was to determine the extent of the association between objectively measured physical activity and changes in adiposity in middle-age women over a 20 month period using precise measurement methods. Ancillary objectives were to examine the extent to which potentially confounding factors, including dietary energy intake, baseline physical activity, and age influenced the association between changes in physical activity and body composition over time. Cross-sectional data from the present cohort has previously been reported, which demonstrated an inverse relationship between physical activity and adiposity [14]. These crosssectional findings offer insight into the relationship between physical activity and adiposity. However, prospective research is needed to determine the true relationship over time.

\section{METHODS}

\section{Subjects}

Subjects for this study were comprised of an existing cohort of 275 healthy women. Of the original cohort of 275, 256 were included in the 20-month follow up assessment. Subjects from the original cohort were dropped from the study for various reasons, including relocating from the area, not willing to continue in the cohort, and missing data. The women in this cohort were recruited using various channels, including community organizations and worksites. To control for the influence of cigarette smoking and pregnancy on weight gain, only nonsmokers and women not planning to become pregnant were included in the cohort. To diminish the bias of underreporting of dietary intake, those who consumed less than $130 \%$ of their estimated resting metabolic rate at baseline were asked to redo their dietary intake assessment [15]. Only women were included in the study to control for potential gender differences related to body fat and body weight change.

\section{Data Collection Procedure}

Each assessment period required subjects come to the research facility two different times for testing. These testing sessions occurred one week apart. Subjects were asked to fast for approximately three hours before coming to their appointment, although water was permissible.

\section{Physical Activity}

Physical activity was measured for seven consecutive days at baseline and again at follow-up using ActiGraph (formerly CSA) accelerometers (Health One Technology, Fort Walton Beach, Florida) [16,17]. Research has shown that ActiGraph monitors are both valid and reliable for measuring physical activity in humans [18-21]. Treadmill studies have concluded that the ActiGraph data is also reproducible [22]. Use of the accelerometer allowed daily activities, such as walking, jogging, and periods of little movement, including sitting and sleeping, and the intensity of these activities, to be monitored.

Subjects wore the activity monitors for 7 consecutive days. The monitors were worn at all times except while bathing. The monitors were programmed to sum the physical activity counts and give a reading every 10 minutes for each subject. This provided 144 activity counts per subject over a 24-hour period.
Over the 7-day assessment period, there were 1008 activity counts. Average daily activity counts divided by 1000 was used to index total daily physical activity.

\section{Body Composition}

Body composition was measured at both baseline and 20month follow up using Life Measurement Instrument's Bod Pod (Concord, CA). Before each body composition assessment, the Bod Pod was calibrated with a known-volume cylinder. Subjects wore a snug fitting one-piece nylon swimsuit provided by the lab. All swimsuits were of a standardized style to eliminate error due to volume differences in swimsuit artifact. All subjects also wore a lycra swim cap provided by the lab during testing. Lung volume was entered using the lung volume measure obtained at baseline. This reduced the threat of having differences in body composition due to lung volume measurement error. Body composition measurements were taken until two body fat percentage results within one percentage point of each other were achieved, these two values were averaged to index percent body fat. This rarely required more than two trials. The body volume measurements obtained by the Bod Pod were converted to whole body density and body fat using Siri's equation [22].

Reliability of the Bod Pod was tested using 100 subjects from the study. A test-retest protocol was used with subjects completely repositioned between the first and second tests. A very strong intraclass correlation $(r=0.999)$ was found between the two tests.

\section{Body Weight}

Body weight was measured using a computerized electronic scale (Tanita Corp, Tokyo, Japan) with subjects in a standard, dry, one-piece nylon swim suit provided by the lab. Subjects were required to use the restroom before being assessed. The scale was calibrated using known weights before each subject was weighed. The scale gives readings via a computer interface to the nearest 5 grams. Subjects were requested to not eat for 3 hours prior to their visit to the lab. Each subject was weighed twice, one week apart, and the average of the two measurements was used to represent the subject's body weight.

\section{Dietary Energy Intake}

Dietary energy intake was measured using the 7-day weighed food record method. This method of dietary intake measurement is considered to be a precise and representative field measure of dietary intake, especially when repeated measures are taken over time [23-25].

Before beginning their 7-day record, all subjects were individually trained using plastic food models and counseled strongly to record everything they consumed, including both food and drink, during the subsequent 7-day recording period. All subjects were trained with and loaned a calibrated Ohaus 2000 portable electronic scale (Florham Park, NJ), which gives digital readings to the nearest gram. Subjects used the scales to weigh everything they ate and drank during the 7-day recording period.

Extra effort was made to minimize the tendency of subjects to underreport food intake. The problem of underreporting of energy intake seems to be strongly related to BMI. As BMI 
Table 1. Changes in Key Variables Over the 20-month Study Period

\begin{tabular}{|c|c|c|c|c|}
\hline Variable & $\begin{array}{c}\text { Baseline } \\
\text { Mean (SD) }\end{array}$ & $\begin{array}{c}\text { 20-Month } \\
\text { Mean (SD) }\end{array}$ & F -Value \\
\hline \hline Body fat \% & $31.7(7.1)$ & $32.7(7.7)$ & 13.0 & 0.0004 \\
\hline Weight (lbs.) & $66.1(10.4)$ & $66.91(11.0)$ & 5.0 & 0.005 \\
\hline Body mass index & $23.8(3.4)$ & $24.1(3.6)$ & 8.2 & 0.023 \\
\hline Activity* & $2736.0(783.4)$ & $2587.3(894.2)$ & 20.2 & $<004$ \\
\hline Intake (kcal/day) & $2056.7(308.1)$ & $1962.2(309.1)$ & $<001$ \\
\hline
\end{tabular}

Note: $\mathrm{F}$ and p-values are based on the mean difference score.

*Physical Activity=Activity counts/1000.

increases, the degree of dietary intake underreporting increases, making it a particular problem among obese subjects [26-28]. This potential problem was addressed using three strategies at baseline and follow-up. First, subjects were given strong counsel to record everything they consumed and to eat a normal diet. Second, each subject was given a personal telephone call every other day during the 7-day food-recording period. During these calls, subjects were reminded of the importance of eating as they normally would and recording everything they consumed. Third, subjects who reported unrealistic energy intakes ( $<130 \%$ of Resting Metabolic Rate (RMR)) were asked to redo their diet records. Subjects who refused were not included as cohort participants [29]. The ESHA software program (Salem, OR), version 7.6, was used to analyze the food records. The same individual entered all diet information during both baseline and follow-up assessments. This eliminated the contribution of inter-tester variance on differences in energy intake.

\section{Statistical Analysis}

All statistical analyses were computed using the SAS ${ }^{\circledR}$ system (Cary, NC). Changes in the major variables were calculated by subtracting baseline scores from follow-up scores. For example, changes in physical activity over the study period were found by subtracting physical activity counts at baseline from those received at follow-up.

Regression analysis using the general linear model (GLM) procedure was used to determine the extent to which changes in physical activity contributed to changes in body fat percentage and body weight over the study period. Partial correlation was employed to statistically adjust for potentially confounding variables such as age and baseline energy intake. Further analysis was conducted by dividing the subjects into three groups. Specifically, those who gained, lost, or maintained body fat percentage. Additionally, subjects were divided into groups based on those who gained, lost, or maintained body weight. Regression analysis was used to determine the extent to which the groups differed in changes in physical activity over the study period. Contrast coding was used to allow comparisons between specific body fat and body weight change groups.

Relative risk was calculated using a modified Poisson regression approach as explained by Zou [30]. For the relative risk analysis, subjects were placed into three groups based on physical activity change from baseline to the 20-month follow up. Relative risk ratios were calculated for change in body fat and body weight comparing those who decreased physical ac- tivity to those who maintained or increased activity. The relative risk ratios were adjusted by controlling for the influence of potential confounding factors, such as initial body fat or body weight, age, energy intake at both assessments, and baseline physical activity level.

\section{RESULTS}

Of the 275 subjects tested at baseline, 256 were included in the 20-month follow-up analysis. The average number of days between the baseline and follow-up assessments was $598 \pm 68$ days. Subjects included in this analysis had an average age of $39.9 \pm 3.1$ years, were largely Caucasian (95.9\%), educated ( $94 \%$ with some college, $56.1 \%$ college graduates), and married $(84.5 \%)$.

\section{Changes in Variables over 20-Months}

Mean weekly physical activity decreased $5 \%$ from baseline to follow-up in the present cohort of women $(p<0.01)$ (see Table 1). On average, participants gained $0.8 \pm 3.9 \mathrm{~kg}$ from baseline to follow-up $(p<0.01)$. Evaluation of the changes in body weight over the 20 -month period showed that $33 \%$ of the women gained more than 2 kilograms, $18 \%$ lost more than 2 kilograms, and $47 \%$ maintained their weight within 2 kilograms of baseline values. Body Fat Percentage (BF\%) also increased significantly, from $31.6 \pm 7.1 \%$ to $32.6 \pm 7.7 \%$ ( $p$ $<0.01)$. A total of $119(52.2 \%)$ of the participants increased $\mathrm{BF} \%$ by at least 1 percentage point (e.g., $32 \% \mathrm{BF}$ to $\geq 33 \%$ $\mathrm{BF}), 53(23.2 \%)$ maintained $\mathrm{BF} \%$ within \pm 1 percentage point, and $56(24.6 \%)$ decreased $\mathrm{BF} \%$ by at least one percentage point.

\section{Physical Activity and Body Fat}

Baseline physical activity levels were not predictive of changes in body fat across the three body fat change groups over the study period $(\mathrm{F}=0.53, \mathrm{p}=0.59)$. After controlling for age, baseline energy intake, there were still no differences in baseline physical activity among the body fat change groups.

Table 2 indicates that changes in physical activity over the 20 -month period were predictive of body fat changes in the cohort. Women who increased physical activity over the study period tended to decrease body fat percentage, whereas those who decreased physical activity demonstrated an increase in body fat percentage $(\mathrm{F}=5.29, \mathrm{p}=0.022)$. Those who maintained their body fat percentage over the study period were not 
Table 2. Mean Changes in Physical Activity Across Body Composition Change Groups with Control for Potential Confounders

\begin{tabular}{|c|c|c|c|c|c|c|c|c|}
\hline \multirow{2}{*}{ Variable } & \multicolumn{2}{|c|}{$\begin{array}{c}\text { Decreased BF\% } \\
\quad(\mathrm{N}=64)\end{array}$} & \multicolumn{2}{|c|}{$\begin{array}{l}\text { Maintained BF\% } \\
\qquad(\mathrm{N}=61)\end{array}$} & \multicolumn{2}{|c|}{$\begin{array}{l}\text { Increased BF\% } \\
\qquad(\mathbf{N}=131)\end{array}$} & \multirow[t]{2}{*}{$\boldsymbol{F}$} & \multirow{2}{*}{$P$} \\
\hline & Mean & SD & Mean & SD & Mean & SD & & \\
\hline Physical activity change & $38.4^{*}$ & 1003.8 & -130.0 & 662.4 & -248.3 & 65.2 & 5.3 & 0.0223 \\
\hline \multicolumn{9}{|l|}{ Controlling for: } \\
\hline Change in kcal & $34.6^{*}$ & & -130.9 & & -246.0 & & 4.8 & 0.0297 \\
\hline Baseline PA, kcal & $16.0^{*}$ & & -133.0 & & -236.0 & & 4.3 & 0.0461 \\
\hline Age, baseline BF\%, kcal change & $32.8^{*}$ & & -130.0 & & -245.5 & & 4.6 & 0.0336 \\
\hline Age, baseline PA, kcal change & $11.5^{*}$ & & -132.1 & & -234.4 & & 4.0 & 0.0474 \\
\hline
\end{tabular}

Those who increased BF\% increased by more than 1 percentage point.

Those who decreased $\mathbf{B F} \%$ decreased by more than 1 percentage point.

Those who maintained BF\% were between -1 and 1 percentage point change from baseline to follow-up.

Negative values reflect a decrease in total physical activity from baseline.

Means on the same row as a control variable, such as age, have been adjusted for differences in the control variable(s).

Physical Activity=Activity counts/1000.

$*=$ Group means are significantly different from the Increased BF\% group $(P<0.05)$.

Table 3. Mean Changes in Physical Activity Across Body Weight Change Groups with Control for Potential Confounders

\begin{tabular}{|c|c|c|c|c|c|c|c|c|}
\hline \multirow{2}{*}{ Variable } & \multicolumn{2}{|c|}{$\begin{array}{c}\text { Decreased BW } \\
\qquad(N=48)\end{array}$} & \multicolumn{2}{|c|}{$\begin{array}{l}\text { Maintained BW } \\
\quad(\mathrm{N}=126)\end{array}$} & \multicolumn{2}{|c|}{$\begin{array}{c}\text { Increased BW } \\
\qquad(\mathrm{N}=82)\end{array}$} & \multirow{2}{*}{$\boldsymbol{F}$} & \multirow{2}{*}{$P$} \\
\hline & Mean & SD & Mean & SD & Mean & SD & & \\
\hline Physical activity change & $120.6^{*}$ & 1020.8 & -199.0 & 712.1 & -218.0 & 647.4 & 5.1 & 0.0249 \\
\hline \multicolumn{9}{|l|}{ Controlling for: } \\
\hline Change in kcal & $124.2^{*}$ & & -199.5 & & -219.2 & & 4.67 & 0.0319 \\
\hline Baseline PA, kcal & 133.5 & & -148.6 & & -246.0 & & 3.39 & 0.0669 \\
\hline Age, baseline BW, kcal change & $130.0^{*}$ & & -206.5 & & -211.8 & & 4.64 & 0.0324 \\
\hline Age, baseline PA, kcal change & 129.9 & & -148.0 & & -245.0 & & 3.28 & 0.0723 \\
\hline
\end{tabular}

Those who increased BW increased by more than $2 \mathrm{~kg}$.

Those who decreased BW decreased by more than $2 \mathrm{~kg}$.

Those who maintained BW were between -2 and $2 \mathrm{~kg}$ from baseline to follow-up.

Negative values reflect a decrease in total physical activity from baseline.

Means on the same row as a control variable, such as age, have been adjusted for differences in the control variable(s).

Physical Activity=Activity counts $/ 1000$.

$*=$ Group means are significantly different from the Increased $\mathrm{BF} \%$ group $(P<0.05)$.

more active than those who gained body fat $(\mathrm{F}=0.86, \mathrm{p}=$ 0.35). Controlling for age, change in energy intake, baseline physical activity, and baseline body fat did not influence the significance of the relationship between changes in physical activity and changes in body fat percentage.

Over the 20-months, the subjects who decreased physical activity had a $32 \%$ greater risk of increasing body fat percentage compared to those who maintained or increased physical activity $(\mathrm{RR}=1.32, \mathrm{CI}=1.00-1.78)$. After controlling for all of the potential confounding variables, the group that decreased activity demonstrated a significant $39 \%$ increased risk of gaining body fat $(\mathrm{RR}=1.39, \mathrm{CI}=1.02-1.90)$. (See Table 4)

\section{Physical Activity and Body Weight}

Baseline physical activity was predictive of weight change across the study. Specifically, women who lost weight during the study tended to be significantly less active at baseline than those who maintained weight $(\mathrm{F}=12.82, \mathrm{p}=0.0004)$. Adjusting for baseline energy intake slightly strengthened these differences. 
Table 4. Risk of Weight or Fat\% Gain in Women Who Decreased Physical Activity Compared to those who Maintained or Increased Physical Activity

\begin{tabular}{|c|c|c|c|c|}
\hline \multicolumn{5}{|c|}{ Outcome } \\
\hline Risk Factor: & $\mathbf{R} \mathbf{R}^{\dagger}$ & $95 \% \mathrm{CI}^{+}$ & $\mathbf{R R}$ & $95 \% \mathrm{CI}$ \\
\hline $\begin{array}{c}\text { With Control for Confounding } \\
\text { Factors* } \\
\text { Decreased PA }\end{array}$ & 1.54 & $1.08-2.20$ & 1.38 & $1.02-1.90$ \\
\hline
\end{tabular}

${ }^{\dagger} \mathrm{RR}=$ Relative Risk; ${ }^{\ddagger} \mathrm{CI}=$ Confidence Interval; intervals with both values $\geq 1$ indicate that the $\mathrm{RR}$ is statistically significant $(\mathrm{p}<0.05)$.

* Confounding variables controlled for: Initial body weight, initial body fat, energy intake at both assessments, age, and baseline physical activity.

Weight Gain $=$ Those who increased body weight by more than $2 \mathrm{~kg}$.

Fat $\%$ Gain $=$ Those who increased body fat percentage by more than one percentage point.

Table 3 shows that changes in physical activity from baseline to the 20-month follow-up were predictive of changes in body weight among participants. Women who increased physical activity tended to decrease body weight. In contrast, those who decreased in physical activity tended to increase in body weight over the 20 -month period $(\mathrm{F}=5.11, \mathrm{p}=0.025)$. However, those who maintained weight over the study period did not participate in more physical activity than those who gained weight $(F=0.03, p=0.87)$. Controlling for age, change in energy intake, and baseline body weight tended to weaken the findings slightly, but they remained significant. However, adjusting for baseline physical activity and change in energy intake weakened the results to the point where physical activity was no longer predictive of changes in body weight $(\mathrm{F}=3.39$, $\mathrm{p}=0.067$ ).

In regards to the relative risk of body weight gain, there was a significant increase in weight gain risk for those who decreased physical activity $(\mathrm{RR}=1.41, \mathrm{CI}=1.00-2.00)$. After controlling for energy intake, initial body weight, age, and baseline physical activity, those who decreased physical activity realized a 54\% increase in risk for body weight gain compared to those who maintained or increased physical activity status $(\mathrm{RR}=1.54, \mathrm{CI}=1.08-2.2)$. (See Table 4).

\section{DISCUSSION}

The primary aim of the present study was to examine the contribution that changes in physical activity had on changes in body fat and body weight in middle-age women over a 20month period. A prospective design with no intervention was used to examine these relationships. To date, few if any prospective studies have used precise measures of physical activity, dietary intake, and body composition in combination like the present study. Therefore, the results of this study hold important implications in the study of obesity, body fat change, and body weight change.

From baseline to 20-month follow-up, changes were identified in most of the variables tested. Significant changes occurred in body fat percentage, body weight, physical activity and energy intake. Apparently, the major constructs associated with obesity are dynamic in middle-age women over a 20 month period.
As a group, this cohort increased their BF\% and body weight over the study period. The majority of the subjects gained more than one percentage point body fat. About one in four women lost more than one percentage point body fat. Regarding weight, one in three gained more than $2 \mathrm{~kg}$ body weight, while one in eight lost more than $2 \mathrm{~kg}$ body weight. Post hoc analysis revealed that there was a strong association ( $\mathrm{r}$ $=0.83, \mathrm{p}=0.01$ ) between changes in body weight and changes in body fat. However, one third of the change in body fat was unaccounted for by the change in body weight. Therefore, it appears critical for researchers to measure both body fat percentage and body weight in future studies of this nature.

Change in objectively measured physical activity was predictive of changes in body fat and body weight over the 20 month period. Women who increased their physical activity tended to have a decreased in body fat and weight over the study period. Those who decreased physical activity tended to have an increase in body fat and weight. This association remained significant, even after controlling for changes in energy intake and other potential confounding factors. Therefore, it appears that changes in physical activity are independently associated with changes in body fat and weight in middle-age women.

There was also a significant increase in risk of both fat and weight gain over the study period for those who decreased their physical activity levels compared to those who maintained or increased their level of activity. This increase slightly increased after controlling for potential confounding variables such as dietary intake, initial weight or fat status, and age. This demonstrates the multivariate nature of changes in body weight and fat. It also demonstrates the need to control for potential confounding factors when assessing risk in obesity related studies.

To date, most investigations of the relationship between physical activity and body composition have been crosssectional in nature. Studies of this type cannot determine timeorder relationships or risk of fat and weight gain. In other words, they cannot identify what occurs first: Do people become inactive resulting in weight gain, or do they gain weight and then become inactive? To examine the sequencing of these events, prospective designs are needed. This study used a prospective design and found that those who became less active over time gained body fat and weight, and those who became 
more active over time lost body fat and weight. It also showed that those who become less active have a significant risk of both fat and weight gain.

Other prospective studies examining the influence of physical activity change on changes in body fat and weight have shown mixed results, but most investigations have found results similar to those in the present study [31-34]. However, previous epidemiologic studies have relied on subjective recall measures of physical activity. Furthermore, previous studies have often neglected to control for the influence of potential confounding factors when examining the influence of physical activity on body fat and body weight. The present study used an objective measure of physical activity that reduced the risk of self-report bias. In addition, several potential confounding factors, including energy intake, were taken into account. Hence, the present study reflects a precise and objective examination of the relationship between physical activity, changes in physical activity, and changes in body fat, and weight over a long duration.

A potential limitation of this study is the inherent complications regarding the assessment of dietary intake in weight or body fat based change studies. In particular, the phenomenon of increased underreporting of dietary intake as BMI increases becomes a concern. In the present study dietary energy intake was used as a potential confounding variable. Several steps were taken to reduce the risk of underreporting as explained in the methods section of this paper. The primary method used to help diminish the risk of underreporting was the use of a sevenday weighed food record as opposed to a simple dietary recall. Despite these proactive steps there is still a risk that underreporting of energy intake did occur. However, it is felt that by taking a proactive approach to underreporting that the risk of underreporting was diminished.

Due to the prospective design of the present study, with no intervention, causality cannot be determined. However, use of a prospective design allowed for examination of the contribution of physical activity and changes in physical activity on changes in body fat and body weight over time.

\section{CONCLUSION}

These findings lend credence to the energy expenditure portion of the energy balance model of weight management. Physical activity is an independent predictor of change in body fat and weight over time. In conclusion, decreasing physical activity over time seems to increase risk of both fat and weight gain. The findings of this study are specific to middle agewomen ages 35-45 and need to be replicated in other populations.

\section{REFERENCES}

[1] Grundy SM. Multifactorial causation of obesity: implications for prevention. Am J Clin Nutr 1998; 67(Suppl): 563S-572S.

[2] Bray GA. Complications of obesity. Ann Intern Med 1985; 103(Suppl 6, Pt 2): 1052-62.

[3] Lee I-M, Manson JE, Hennekens CH, Paffenbarger RS. Body weight and mortality: a 27-year follow-up of middle-aged men. J Am Med Assoc 1993; 270: 2823-8.

[4] Manson JE, Willett WC, Stampfer MJ, et al. Body weight and mortality among women. N Engl J Med 1995; 333: 677-85.

[5] Kissebah AH, Freedman DS, Peiris AN. Health risks of obesity. Med Clin North Am 1989; 73(1): 111-9.
[6] Lolotkin RL, Head S, Hamilton M, Tse C-KJ. Assessing impact of weight on quality of life. Obes Res 1995; 3: 49-56.

[7] Stunkard AJ, Wadden TA. Psychological aspects of severe obesity. Am J Clin Nutr 1992; 55: 524S-532S.

[8] Klesges RC, Klem ML, Hanson CL, et al. The effects of an applicants health status and qualifications on simulated hiring decisions. Int J Obes 1990; 14: 527-35.

[9] Jakicic JM, Otto AD. Physical activity considerations for the treatment and prevention of obesity. Am J Clin Nutr 2005; 82: 226S-229S.

[10] Ballor DL, Keesey RE. A meta-analysis of the factors affecting exercise-induced changes in body mass, fat mass and fat-free mass in males and females. Int J Obes 1991; 15: 717-26.

[11] Poirier P, Despres JP. Exercise in weight management of obesity. Cardiol Clin 2001; 19(3): 459-470.

[12] DiPietro L. Physical activity in the prevention of obesity: current evidence and research issues. Med Sci Sports Exerc 1999; 31: S542S546.

[13] DiPietro L. Physical activity, body weight, and adiposity: an epidemiologic perspective. Exerc Sport Sci Rev 1995; 23: 275-303.

[14] Tucker LA, Peterson TR. Objectively measured intensity of physical activity and adiposity in middle-aged women. Obes Res 2003; 11 : 1581-7.

[15] Goldberg GR, Black AE, Jebb SA, et al. Critical evaluation of energy intake data using fundamental principles of energy physiology: Derivation of cut-off limits to identify under-recording. Eur J Clin Nutr 1991; 45: 569-81.

[16] Trost SG, McIver KL, Pate RR. Conduction accelerometer-based activity assessment in field-based research. Med Sci Sports Exerc 2005; 37: S531-S43.

[17] Ward DS, Evenson KR, Vaughn A, Rodgers AB, Troiano RP. Accelerometer use in physical activity: best practices and research recommendations. Med Sci Sports Exerc 2005; 37: S582-S588.

[18] Baxter B, Nichols JF, Sallis JF, Calfas KJ. Validity and reliability of the CSA accelerometer worn on the ankle, hip, and wrist. Med Sci Sports Exerc 1998; 30(Suppl 5): 10S.

[19] Nelson TE, Leenders NYJM, Sherman WM. Comparison of activity monitors worn during treadmill walking. Med Sci Sports Exerc 1998; 30(Suppl 5): 11S.

[20] Melanson EL, Freedson PS. Validity of the computer science and applications, Inc. (CSA) activity monitor. Med Sci Sports Exerc 1995; 27: 934-40.

[21] Trost SG, Ward DS, Moorehead SM, Watson PD, Riner W, Burke JR. Validity of the Computer Science and Applications (CSA) activity monitor in children. Med Sci Sports Exerc 1998; 30: 629-33.

[22] Siri WE. Body composition from fluid spaces and density: analysis of methods. In: Brozek J, Hensel A, Eds. Techniques for Measuring Body Composition. National Academy of Sciences: Washington DC 1961.

[23] Buzzard M. 24-hour dietary recall and food record methods. In: Willett W, Ed. Nutritional Epidemiology 2nd ed. New York: Oxford University Press 1998; pp. 50-73.

[24] Willett W, Lenart E. Reproducibility and validity of food-frequency questionnaires. In: Willett W, Ed. Nutritional Epidemiology $2^{\text {nd }}$ ed. New York: Oxford University Press 1998; pp. 101-47.

[25] Willett W. Nature of variation in diet. In: Willett W, Ed. Nutritional Epidemiology. 2nd ed. New York: Oxford University Press 1998; pp. 33-49.

[26] Prentice AM, Black AE, Coward WA, Cole TJ. Energy expenditure in overweight and obese adults in affluent societies: an analysis of 319 doubly labeled water measurements. Eur J Clin Nutr 1996; 50: 93-7.

[27] Ballard-Barbash R, Garubard I, Krebs-Smith SM, Schatzkin A, Thompson FE. Contribution of dieting to the inverse association between energy intake and body mass index. Eur J Clin Nutr 1996; 50: 98-106.

[28] Heitmann BL, Lissner L. Dietary underreporting by obese individuals—is it specific or non-specific? Br Med J 1995; 311: 986-9.

[29] Garn SM, Clark DC. Trends in fatness and the origins of obesity. Pediatrics 1976; 57: 443-56.

[30] Zou G. A modified Poisson regression approach to prospective studies with binary data. Am J Epidemiol 2004; 159: 702-6.

[31] Rissanean AM, Heliovaara M, Knekt P. Determinants of weight gain and overweight in adult Finns. Eur J Clin Nutr 1991; 15: 717-26.

[32] French SA, Jeffery RW, Forster JL, McGovern PG, Kelder SH, Baxter JE. Predictors of weight change over two years among a population of working adults: the Healthy Worker Project. Int J Obes 1994; 18: $145-54$. 
[33] Haapanen N, Miilunpalo S, Pasanen M, Oja P, Vuori I. Association between leisure time physical activity and 10-year body mass change among working-aged men and women. Int J Obes 1997; 21: 288-96.
[34] Williamson DF, Madans J, Anda RF, Kleinman JC, Kahn HS, Byers T. Recreational physical activity and ten-year weight change in a US national cohort. Int J Obes 1993; 17: 279-86.

Received: July 03, 2008

(C) Peterson and Tucker; Licensee Bentham Open.

This is an open access article licensed under the terms of the Creative Commons Attribution Non-Commercial License (http://creativecommons.org/licenses/bync/3.0/) which permits unrestricted, non-commercial use, distribution and reproduction in any medium, provided the work is properly cited. 